\title{
Ultrafiltration Rate Effects Declines in Residual Kidney Function in Hemodialysis Patients
}

\author{
Yuji Lee ${ }^{a, b}$ Yusuke Okuda ${ }^{a}$ John Syc Sung Rok Kim ${ }^{b}$ Yoshitsugu Obi ${ }^{a}$ \\ Csaba P. Kovesdy d, e Connie M. Rhee ${ }^{a} \quad$ Elani Streja $^{a} \quad K^{2}$ Kamyar Kalantar-Zadeh ${ }^{a}$ \\ ${ }^{a}$ Harold Simmons Center for Kidney Disease Research and Epidemiology, Division of Nephrology and Hypertension, \\ University of California Irvine Medical Center, Orange, CA, USA; ${ }^{b}$ Division of Nephrology, Department of Medicine, \\ Samsung Changwon Hospital, Sungkyunkwan University School of Medicine, Changwon, South Korea; ' $N e p h r o l o g y$ \\ Section, VA Long Beach Healthcare System, Long Beach, CA, USA; d Division of Nephrology, Department of \\ Medicine, University of Tennessee Health Science Center, Memphis, TN, USA; ${ }^{e}$ Nephrology Section, Memphis \\ Veterans Affairs Medical Center, Memphis, TN, USA
}

\section{Keywords}

Hemodialysis · Residual kidney function · Ultrafiltration rate

\begin{abstract}
Background: High ultrafiltration rate (UFR) has been associated with increased mortality in hemodialysis (HD) patients. However, the impact of UFR on decline of residual kidney function (RKF) has not been elucidated among patients receiving conventional HD. Methods: We performed a retrospective cohort study of 7,753 patients who initiated conventional HD from 2007 to 2011 and survived the first year of dialysis with baseline UFR and renal urea clearance (KRU) data at baseline and 1 year (5th patient-quarter). The primary exposure was average UFR at the $1 \mathrm{st}$ patient-quarter from dialysis initiation ( $<4,4$ to $<6,6$ to $<9,9$ to $<13$, and $\geq 13 \mathrm{~mL} / \mathrm{h} /$ $\mathrm{kg}$ ). Decline in RKF was defined as the percent change in KRU and decline in urine output during the first year after initiation of dialysis. We used a logistic regression model for rapid decline in RKF and a linear regression model for change in urine volume. Results: In our HD cohort, mean baseline UFR
\end{abstract}

\section{KARGER}

(c) 2019 S. Karger AG, Basel

E-Mail karger@karger.com

www.karger.com/ajn was $7.0 \pm 3.1 \mathrm{~mL} / \mathrm{h} / \mathrm{kg}$, and median (interquartile range) baseline KRU was $3.5(2.1-5.3) \mathrm{mL} / \mathrm{min} / 1.73 \mathrm{~m}^{2}$. There was a graded association between UFR and a rapid decline in RKF; the expanded case mix-adjusted ORs and $95 \% \mathrm{Cls}$ were 1.21 (1.04-1.40), 1.34 (1.16-1.55), 1.73 (1.46-2.04), and 1.93 (1.482.52) for baseline UFR 4 to $<6,6$ to $<9,9$ to $<13$, and $\geq 13 \mathrm{~mL} / \mathrm{h} /$ $\mathrm{kg}$, respectively (reference: $<4 \mathrm{~mL} / \mathrm{h} / \mathrm{kg}$ ). KRU trajectories showed a greater KRU decline over time in higher UFR categories. Higher UFR was also associated with a greater decline in urine output after 1 year. Conclusion: Higher UFR was associated with a rapid decline in RKF among conventional HD patients. Further clinical trials are needed to elucidate a causal effect of UFR on RKF among HD patients.

(c) 2019 S. Karger AG, Basel

\section{Introduction}

There has been a growing interest in preservation of residual kidney function (RKF) among hemodialysis (HD) patients alongside endeavors to improve survival 
rate and quality of life $[1,2]$. Even in small amounts, RKF contributes to volume control and clearance of uremic toxins $[3,4]$. In addition, the presence of RKF has been associated with lower concentrations of inflammatory markers and higher levels of nutritional parameters [57]. These beneficial effects of RKF may lead to reduced mortality and better quality of life among HD patients [1, $2,8]$. Thus, preserving RKF should be considered when managing HD patients.

Intradialytic parameters, particularly those affecting hemodynamic stability, may play an important role in preserving RKF [9]. Ultrafiltration rate (UFR) during dialysis can impact hemodynamics, and high UFRs may result in intradialytic hypotension (IDH) and hypoperfusion when the UFR exceeds plasma refilling rate [10-12]. Furthermore, systemic hypoperfusion may cause various complications such as myocardial, brain or intestinal ischemia leading to poor outcomes [13-17]. Given its impact on hemodynamics and organ perfusion, we hypothesize that a higher UFR may also lead to a decreased renal perfusion and precipitate loss of RKF. We thereby sought to evaluate the association of baseline UFR with RKF over 1 year after dialysis initiation among incident conventional HD patients.

\section{Methods}

\section{Study Population}

We examined a statistically deidentified data set of adult ( $\geq 18$ years of age) incident $H D$ patients who received treatment for at least 60 consecutive days in facilities operated by a large dialysis organization in the United States from January 2007 to December 2011. Patients were followed until death, transplantation, loss of follow-up, discontinuation of dialysis or December 31, 2011, whichever occurred first. The follow-up period was divided into patient-quarters (91-day periods from the date of conventional HD initiation). Conventional HD patients were defined as those who received in-center HD and did not receive other dialysis modalities including nocturnal HD, peritoneal dialysis, home HD, less-frequent HD ( $\leq 2$ times per week), or frequent HD ( $>3$ times per week) for at least 45 days within the first patient-quarter. We excluded patients who had missing data or a null value on baseline UFR or renal urea clearance (KRU), or had missing data on KRU at 1 year (5th patient-quarter). The study was approved by the Institutional Review Board of the University of California Irvine with a waiver of informed consent because it contained statistically deidentified information

\section{Demographic and Laboratory Measurements}

Information on age, gender, race/ethnicity, cause of end-stage renal disease (ESRD), primary insurance, comorbidities, dialysis prescription, and laboratory variables were extracted from the statistically deidentified dataset. Predialysis blood samples were processed by standardized methods at a central laboratory in Deland,
Florida, within $24 \mathrm{~h}$ of collection. Repeated measures of laboratory variables for each patient during the patient-quarter were averaged to minimize measurement variability. Quarterly means were used in all analyses. Values extracted from the first patient-quarter served as the baseline data.

\section{Exposure and Outcome Definition}

The primary exposure was the average UFR in the first-patientquarter (i.e., baseline UFR), which was calculated as follows:

$$
\mathrm{UFR}(\mathrm{mL} / \mathrm{h} / \mathrm{kg})=\frac{(\text { preHD weight }- \text { postHD weight })(\mathrm{kg})}{\text { session duration }(\mathrm{h}) \times \text { postHD weight }(\mathrm{kg})} \times 1,000(\mathrm{~mL} / \mathrm{kg})
$$

We then divided baseline UFR into 5 exposure categories $(<4$, 4 to $<6,6$ to $<9,9$ to $<13$, and $\geq 13 \mathrm{~mL} / \mathrm{h} / \mathrm{kg}$ ) [16].

The primary outcome was the RKF after 1 year from dialysis initiation. RKF was first defined using KRU, which was calculated using the formula below, adjusted for body surface area and expressed as $\mathrm{mL} / \mathrm{min} / 1.73 \mathrm{~m}^{2}[18]$.

$$
\mathrm{KRU}(\mathrm{mL} / \mathrm{min})=\frac{\text { Urinary urea nitrogen }\left(\frac{\mathrm{mg}}{\mathrm{dL}}\right) \times \text { urinary volume }(\mathrm{mL})}{\text { collected time }(\mathrm{min}) \times\left[0.9 \times \text { serum urea nitrogen }\left(\frac{\mathrm{mg}}{\mathrm{dL}}\right)\right]}
$$

Then, the percent change from baseline KRU to the average KRU at the 5 th patient-quarter was calculated. We defined a rapid decline in RKF as the percent change in KRU greater than the median for our cohort. Similarly, we assessed the change of urine volume ( $\Delta$ urine volume) from baseline to the 5 th patient-quarter.

\section{Statistical Methods}

Baseline characteristics were described across UFR categories, and trends across categories were evaluated using either a linear regression model or a Wilcoxon-type nonparametric trend test, as appropriate.

We first assessed the association between UFR and a rapid decline in RKF using logistic regression models and using UFR category $<4 \mathrm{~mL} / \mathrm{h} / \mathrm{kg}$ as reference. Three hierarchical adjustment models were examined: (1) an unadjusted model; (2) a case mixadjusted model that included age, gender, race/ethnicity (Caucasian, African American, Hispanic, or other), cause of ESRD (diabetes, hypertension, or other), primary insurance (Medicare, Medicaid, or other), and comorbidities (diabetes, hypertension, congestive heart failure, and cardiovascular disease); (3) an expanded case mix-adjusted model that additionally included baseline KRU, IDH, body mass index (BMI), and normalized protein catabolic rate (nPCR). We defined IDH as HD sessions with absolute nadir systolic blood pressure $<90 \mathrm{~mm} \mathrm{Hg}$ per HD session. We performed a subgroup analysis to assess if we could elicit any factors that could be contributing to the association between UFR and a rapid decline in RKF using categories of $\mathrm{UFR}<4,4$ to $<9$, and $\geq 9$ $\mathrm{mL} / \mathrm{h} / \mathrm{kg}$ (reference, $<4 \mathrm{~mL} / \mathrm{h} / \mathrm{kg}$ ). We utilized likelihood ratio testing and the addition of the following interaction terms into our logistic regression model: age ( $\geq 65$ or $<65$ years old), gender, race (African American or non-African American), diabetes, congestive heart failure, BMI, baseline KRU $\left(\geq 3\right.$ or $\left.<3 \mathrm{~mL} / \mathrm{min} / 1.73 \mathrm{~m}^{2}\right)$, $\mathrm{nPCR}(\geq 0.8$ or $<0.8 \mathrm{~g} / \mathrm{kg} /$ day), and IDH. In sensitivity analysis, we 
additionally adjusted for interdialytic weight gain (IDWG) in addition to all covariates included in an expanded case mix-adjusted model. Moreover, we did a sensitivity analysis with the exclusion of BMI in the expanded case mix-adjusted model since body weight was reflected into UFR.

We then attempted to estimate the magnitude and rate of renal function decline over 1 year according to the baseline UFR categories. We utilized a linear mixed-effects model allowing for a random intercept and slope using an unstructured covariance matrix where UFR categories, case mix variables, baseline KRU, and an interaction term between the patient-quarters and UFR categories were included. We also assessed the change in volume over the same year period as a surrogate marker of RKF using a linear regression model with the 3 previously mentioned levels of adjustments.

We assessed missing baseline data in our covariates and found that nPCR had missing data in $3.7 \%$ of patients in our cohort. To account for this, we performed multiple imputation methods using sequential generalized regression (known as chained equation). We included expanded case mix variables in the imputation model using ten imputed datasets. The estimates were combined using Rubin's rules [19]. Statistical analyses used STATA, version 13.1 (StataCorp LP, College Station, TX, USA).

\section{Results}

\section{Patient Characteristics}

Among 147,273 patients receiving conventional HD available for analysis, we excluded 22,427 patients with missing data on baseline UFR. We then excluded 82,848 patients with missing data on baseline KRU and 1,676 patients with zero KRU at baseline. Then, we excluded 32,569 patients with missing data on KRU at the fifth patient-quarter (i.e., the first 91-day period of the second year of dialysis). Our study cohort finally consisted of 7,753 conventional HD patients (online suppl. Fig. 1; for all online suppl. material, see www.karger.com/doi/10.1159/000503918).

In our cohort, mean age was $62 \pm 14$ years, $65 \%$ were male, 56\% were Caucasian, 25\% were African American, $49 \%$ had ESRD due to diabetic nephropathy, and mean baseline UFR level was $7.0 \pm 3.1 \mathrm{~mL} / \mathrm{h} / \mathrm{kg}$, (Table 1). $\mathrm{Pa}$ tients with a higher UFR had lower baseline KRU, lower urine volume, lower BMI, greater nPCR, and greater decrease in intradialytic systolic blood pressure during HD.

\section{Association of Baseline UFR with a Rapid Decline in $R K F$}

The median (interquartile range [IQR]) of KRU at baseline and 1 year was $3.5(2.1-5.3)$ and $2.2(1.0-3.9) \mathrm{mL} /$ $\mathrm{min} / 1.73 \mathrm{~m}^{2}$, respectively $(p<0.001)$. The number of patients with rapid decline in RKF was 522 (43\%), 950 (48\%),
1,393 (50\%), 822 (56\%), and 189 (59\%) for baseline UFR of $<4,4$ to $<6,6$ to $<9,9$ to $<13$, and $\geq 13 \mathrm{~mL} / \mathrm{h} / \mathrm{kg}$, respectively $(p<0.001)$. Across all levels of adjustment, there was an incremental association between baseline UFR and higher odds of rapid decline in RKF ( $p$ for linear trend $<0.001$; Fig. 1). The expanded case mix-adjusted ORs and 95\% CIs were 1.21 (1.04-1.40), 1.34 (1.16-1.55), 1.73 (1.46-2.04), and 1.93 (1.48-2.52) for baseline UFR of 4 to $<6,6$ to $<9,9$ to $<13$, and $\geq 13 \mathrm{~mL} / \mathrm{h} / \mathrm{kg}$, respectively (reference: UFR $<4 \mathrm{~mL} / \mathrm{h} / \mathrm{kg}$ ). When we did a sensitivity analysis with the exclusion of BMI in the expanded case mixadjusted model since body weight was reflected into UFR, the results were unchanged; ORs and 95\% CI were 1.21 (1.04-1.40), 1.34 (1.16-1.55), $1.73(1.47-2.03)$, and 1.92 $(1.48-2.49)$ for baseline UFR of 4 to $<6,6$ to $<9,9$ to $<13$, and $\geq 13 \mathrm{~mL} / \mathrm{h} / \mathrm{kg}$, respectively (reference: UFR $<4 \mathrm{~mL} / \mathrm{h} /$ $\mathrm{kg})$. Furthermore, in sensitivity analysis with additional adjustment for IDWG, the results also remained consistent; ORs and 95\% CI were 1.21 (1.04-1.41), 1.35 (1.161.56), 1.73 (1.46-2.07), and $1.94(1.47-2.56)$ for baseline UFR of 4 to $<6,6$ to $<9,9$ to $<13$, and $\geq 13 \mathrm{~mL} / \mathrm{h} / \mathrm{kg}$, respectively (reference: UFR $<4 \mathrm{~mL} / \mathrm{h} / \mathrm{kg}$ ).

In subgroup analyses, the association between higher baseline UFR and a rapid decline in RKF was modified by race $\left(p_{\text {interaction }}=0.006\right)$; where ORs for UFR $\geq 9 \mathrm{~mL} / \mathrm{h} / \mathrm{kg}$ were drastically attenuated among African Americans (Fig. 2). Although IDH was an effect modifier in the association between UFR and decline in RKF ( $p_{\text {interaction }}=$ 0.02 ), the association was consistent with the overall analysis in both patients with and without IDH. However, the association between UFR and a rapid decline in RKF was not modified by age, gender, diabetes, congestive heart failure, BMI, baseline KRU, and nPCR; $p$ values for interaction were $0.842,0.138,0.677,0.517,0.262,0.230$, and 0.769 , respectively.

\section{Association of UFR and RKF Decline through 1 Year}

The median (IQR) $\Delta$ KRU during the first year after initiation of HD was $-1.11(-2.62$ to -0.18$) \mathrm{mL} /$ $\min / 1.73 \mathrm{~m}^{2}$. When assessing the change in RKF, we found that higher UFR categories exhibited a greater KRU decline over time (Fig. 3). At all time points except baseline (2nd, 3rd, 4th, and 5th patient-quarters), estimated KRU values were lower in higher UFR categories. In particular, 3 months after HD initiation (2nd patientquarter), decline in RKF was steeper in higher UFR categories; differences in estimated KRU from baseline were $-0.02,-0.25,-0.41,-0.70$, and $-0.92 \mathrm{~mL} / \mathrm{min} / 1.73 \mathrm{~m}^{2}$ at UFR of $<4,4$ to $<6,6$ to $<9,9$ to $<13$, and $\geq 13 \mathrm{~mL} / \mathrm{h} / \mathrm{kg}$, respectively. 
Table 1. Baseline characteristics of 7,753 incident conventional hemodialysis patients stratified by baseline UFR

\begin{tabular}{|c|c|c|c|c|c|c|c|}
\hline & \multirow[t]{2}{*}{ All patients } & \multicolumn{5}{|l|}{ UFR, mL/h/kg } & \multirow[t]{2}{*}{$p$ value } \\
\hline & & $<4$ & 4 to $<6$ & 6 to $<9$ & 9 to $<13$ & $\geq 13$ & \\
\hline$n(\%)$ & 7,753 & $1,211(16)$ & $1,980(26)$ & $2,768(36)$ & $1,471(19)$ & $323(4)$ & \\
\hline Age, years & $62 \pm 14$ & $62 \pm 14$ & $62 \pm 14$ & $62 \pm 14$ & $61 \pm 14$ & $59 \pm 15$ & 0.005 \\
\hline Gender, male & 65 & 58 & 61 & 68 & 70 & 65 & $<0.001$ \\
\hline \multicolumn{8}{|l|}{ Race/ethnicity } \\
\hline Caucasian & 56 & 64 & 59 & 55 & 51 & 49 & $<0.001$ \\
\hline African American & 25 & 24 & 26 & 25 & 24 & 18 & 0.03 \\
\hline Hispanic & 10 & 7 & 8 & 11 & 14 & 16 & $<0.001$ \\
\hline Others & 9 & 5 & 7 & 9 & 12 & 17 & $<0.001$ \\
\hline \multicolumn{8}{|l|}{ Cause of ESRD } \\
\hline Diabetes & 49 & 39 & 47 & 52 & 52 & 51 & $<0.001$ \\
\hline Hypertension & 28 & 29 & 28 & 27 & 29 & 32 & 0.9 \\
\hline Others & 23 & 32 & 24 & 21 & 20 & 17 & $<0.001$ \\
\hline \multicolumn{8}{|l|}{ Primary insurance } \\
\hline Medicare & 51 & 50 & 49 & 51 & 52 & 52 & 0.3 \\
\hline Medicaid & 6 & 4 & 6 & 6 & 9 & 9 & $<0.001$ \\
\hline Others & 43 & 46 & 45 & 42 & 39 & 39 & $<0.001$ \\
\hline \multicolumn{8}{|l|}{ Comorbidities } \\
\hline Diabetes & 68 & 61 & 68 & 71 & 69 & 72 & $<0.001$ \\
\hline Hypertension & 52 & 52 & 55 & 50 & 53 & 52 & 0.07 \\
\hline $\mathrm{CHF}$ & 47 & 38 & 46 & 48 & 53 & 51 & $<0.001$ \\
\hline CVD & 25 & 24 & 24 & 26 & 28 & 26 & 0.1 \\
\hline $\mathrm{BMI}, \mathrm{kg} / \mathrm{m}^{2}$ & $29.2 \pm 7.3$ & $31.2 \pm 8.2$ & $31.3 \pm 7.8$ & $29.1 \pm 6.7$ & $26.1 \pm 5.4$ & $22.8 \pm 3.8$ & $<0.001$ \\
\hline $\mathrm{KRU}, \mathrm{mL} / \mathrm{min} / 1.73 \mathrm{~m}^{2}$ & $3.5(2.1-5.3)$ & $4.0(2.5-5.8)$ & $3.6(2.2-5.4)$ & $3.4(2.1-5.2)$ & $3.1(1.8-4.9)$ & $3.3(1.9-4.8)$ & $<0.001$ \\
\hline Urine volume, $\mathrm{mL}$ & $950(550-1,440)$ & $1,150(700-1,700)$ & $1,000(600-1,500)$ & $900(550-1,400)$ & $800(500-1,250)$ & $775(500-1,250)$ & $<0.001$ \\
\hline Ultrafiltration, L & $2.0 \pm 0.9$ & $0.9 \pm 0.5$ & $1.7 \pm 0.6$ & $2.2 \pm 0.7$ & $2.7 \pm 0.7$ & $3.1 \pm 0.8$ & $<0.001$ \\
\hline Dialysis time, min & $208(184-223)$ & $210(186-230)$ & $211(188-231)$ & $208(184-222)$ & $199(182-214)$ & $185(180-210)$ & $<0.001$ \\
\hline Postdialysis weight, kg & $85 \pm 24$ & $92 \pm 26$ & $92 \pm 25$ & $85 \pm 22$ & $75 \pm 17$ & $64 \pm 13$ & $<0.001$ \\
\hline Weekday IDWG & $2.1(1.4-2.9)$ & $0.9(0.5-1.2)$ & $1.5(1.2-1.8)$ & $2.3(1.9-2.6)$ & $3.2(2.8-3.6)$ & $4.3(3.8-4.9)$ & $<0.001$ \\
\hline Weekend IDWG & $2.8(1.9-3.8)$ & $1.1(0.7-1.6)$ & $2.1(1.7-2.6)$ & $3.0(2.5-3.6)$ & $4.2(3.7-4.9)$ & $5.8(5.1-6.7)$ & $<0.001$ \\
\hline Lowest intradialytic SBP, mm Hg & $118 \pm 14$ & $118 \pm 14$ & $119 \pm 14$ & $118 \pm 14$ & $118 \pm 14$ & $117 \pm 14$ & 0.07 \\
\hline $\mathrm{IDH}$ & 65 & 62 & 63 & 65 & 69 & 74 & $<0.001$ \\
\hline nPCR, g/kg/day & $0.83 \pm 0.22$ & $0.78 \pm 0.20$ & $0.80 \pm 0.21$ & $0.84 \pm 0.21$ & $0.87 \pm 0.23$ & $0.92 \pm 0.25$ & $<0.001$ \\
\hline
\end{tabular}

Values for categorical variables are shown as percentages; values for continuous variables are shown as mean \pm SD or median (IQR).

UFR, ultrafiltration rate; ESRD, end-stage renal disease; CHF, congestive heart failure; CVD, cardiovascular disease; BMI, body mass index; IDWG, interdialytic weight gain; KRU, renal urea clearance; SBP, systolic blood pressure; IDH, intradialytic hypotension; nPCR, normalized protein catabolic rate.

Sensitivity Analysis: Urine Output as a Marker of RKF

In our assessment of changes to urine output after the first year on dialysis, the median (IQR) change in urine volume was -250 ( -620 to 100$) \mathrm{mL}$. We found higher baseline UFR categories were associated with a greater decline in urine volume during the first year after initiation of HD compared to the reference category (UFR $<4 \mathrm{~mL} / \mathrm{h} / \mathrm{kg}$ ). After adjusting for case-mix variables, BMI, nPCR, and baseline urine volume, change in urine volume (95\% CI) over 1 year was -96 ( -56 to -136$)$, -159 ( -120 to -198$),-229(-184$ to -274$)$, and -268 $(-196$ to -340$) \mathrm{mL}$ at UFR 4 to $<6,6$ to $<9,9$ to $<13$, and $\geq 13 \mathrm{~mL} / \mathrm{h} / \mathrm{kg}$, respectively (reference: UFR $<4 \mathrm{~mL} / \mathrm{h} / \mathrm{kg}$; Fig. 4).

\section{Discussion}

In this study, we demonstrated that higher UFR is associated with incrementally increased odds of rapid decline in RKF, an association that was interestingly attenuated among African Americans. We also found that higher UFR is associated with steeper declines in RKF and a greater decrease in residual urine volume.

Previous studies have shown that UFR levels of $\geq 9 \mathrm{~mL} / \mathrm{h} / \mathrm{kg}$ are associated with higher mortality [16, 20]. Potential mechanisms underlying this association may be related to circulatory stress and hypotension induced by high UFR. Hypotension may lead to diminished renal blood supply and subsequent nephron loss. Although in our subgroup analysis, IDH was an effect 
Fig. 1. ORs for rapid decline in RKF with 4 levels of adjustment based upon baseline UFR. RKF, residual kidney function; UFR, ultrafiltration rate.

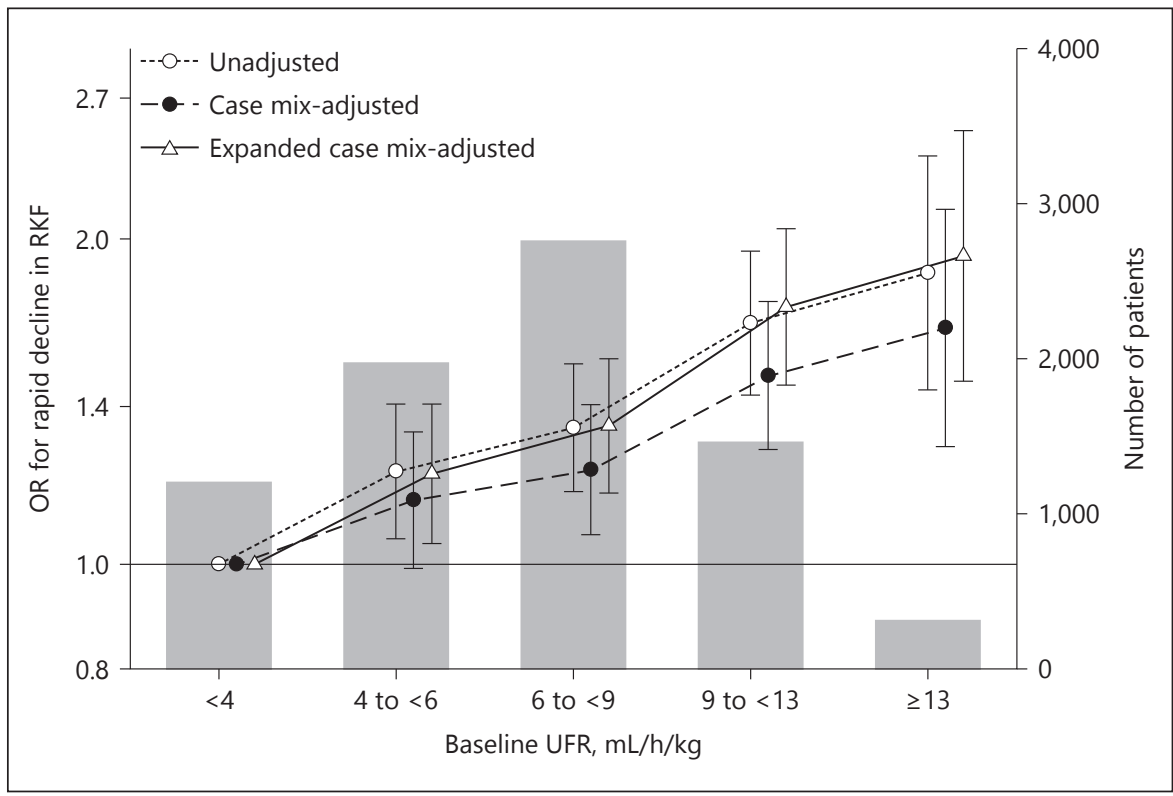

modifier of the association between high UFR and a decline in RKF, high UFR was associated with a decline in RKF among patients without IDH as well as those with IDH. On the one hand, we hypothesize that despite systemic hypotension, autoregulatory mechanisms maintain adequate renal perfusion $[9,21]$. On the other hand, undetected, subclinical hypoperfusion may be occurring despite the absence of systemic hypotension $[9,21,22]$. Unfortunately, our analysis was limited by available data and all episodes of IDH may not have been recorded. Also, our limited definition of IDH may not have captured all clinically relevant episodes of hypotension.

In our study, we also show that individuals exhibit a nonlinear decline in RKF among patients receiving conventional HD. According to the United States Renal Data System 2015 annual data report, a fair number of patients still have RKF at the time of their transition to dialysis [23]. A previous study noted that RKF declines were the greatest within the first 3 months after initiating dialysis [24]. Our analysis not only confirmed that higher UFR is associated with a steeper decline in KRU within the first 3 months but also further goes on to show that this dose-dependent association is continued over the course of the entire year (Fig. 3). Since preservation of renal function may improve survival in dialysis patients, this finding suggests that we should remain cautious about prescribing a high UFR to prevent loss of $\mathrm{RKF}$, especially within the first year after dialysis initiation [2].

UFR and Decline in RKF
The strength of this study is that it showed the impact of high UFR on the decline in RKF in a large cohort of incident conventional HD patients. However, there are several limitations to our study. First, KRU used in this study may not be the best way to measure RKF as it tends to underestimate glomerular filtration rate due to tubular reabsorption. However, our analysis focused on trends in KRU, placing less emphasis on the absolute value of KRU. Second, we only included patients who had KRU data at baseline and 1 year after initiating HD (patients excluded if zero at baseline or missing values at baseline and 1 year). Patients who had limited or no RKF after initiating HD are less likely to have undergone urine collections at 1 year, which might result in potential selection bias. In a sensitivity analysis, we compared our cohort to those who were excluded from the study. We found that the included patients had a higher prevalence of diabetes and congestive heart failure using standardized differences (online suppl. Table 1). Both diabetes and CHF have been associated with a rapid decline in RKF and possibly higher UFR $[25,26]$. While we have attempted to adjust for these comorbidities, any residual effect may bias our study results away from the null. Third, even after we adjusted for potential confounders to investigate the association between UFR and RKF, residual confounding may inherently remain due to the inability to measure some potential confounders and the retrospective observational nature of this study. In addition, due to the observational study design, this study could not thoroughly prove a cause 
Fig. 2. Subgroup analyses of associations between UFR and rapid decline in RKF in the expanded case mix-adjusted model. Points and bars represent ORs and 95\% CIs, respectively. Reference is UFR 4 to $<9 \mathrm{~mL} / \mathrm{h} / \mathrm{kg}$. UFR, ultrafiltration rate; KRU, renal urea clearance; BMI, body mass index; IDH, intradialytic hypotension; nPCR, normalized protein catabolic rate; RKF, residual kidney function.

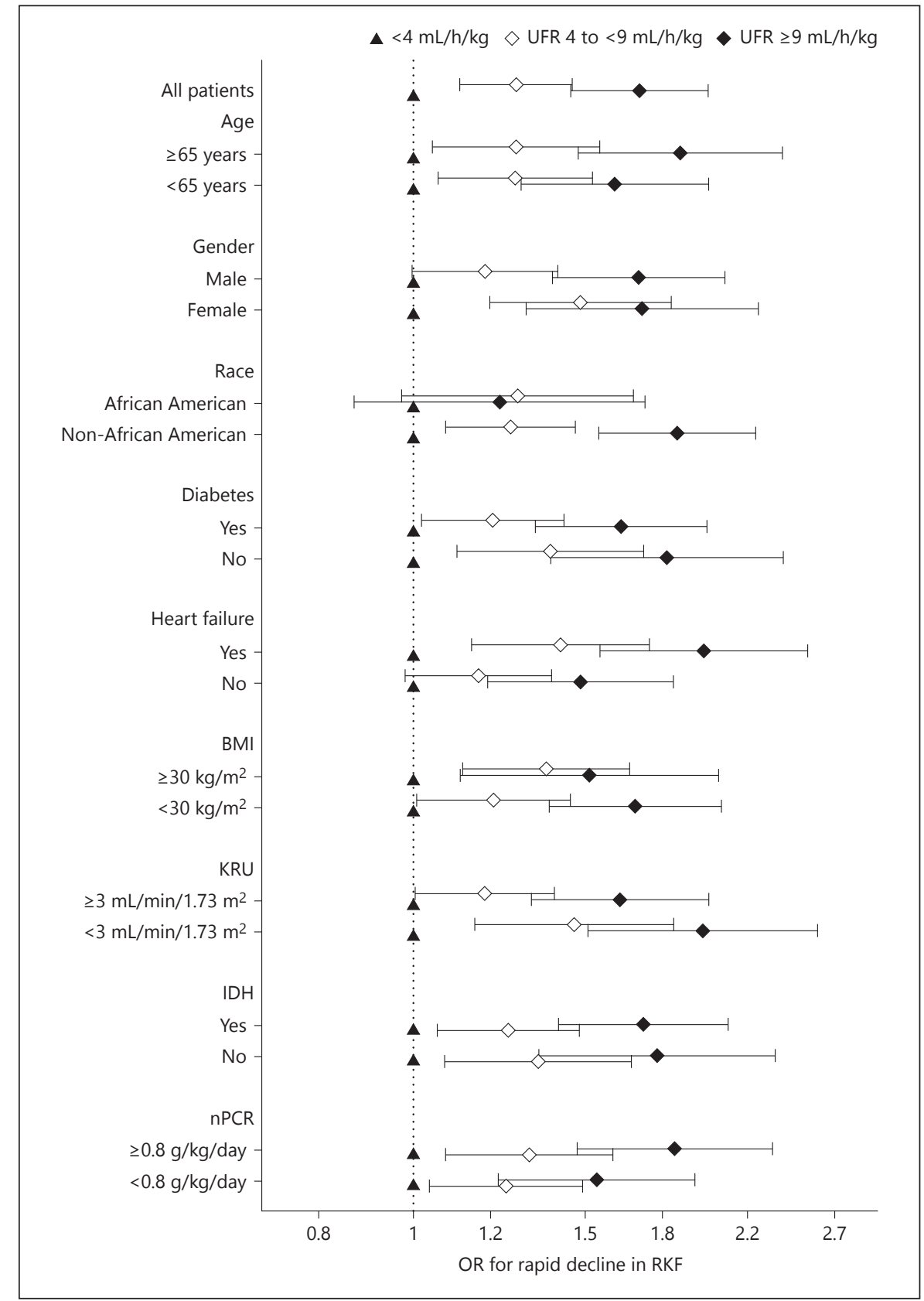

and effect mechanism. Particularly, although the relationship between higher UFR and rapid decline in RKF remained robust even after adjusting for IDWG, IDWG itself may not thoroughly reflect an objective volume status. Therefore, the analyses might have been confounded by volume status. In addition, the diuretic therapy at the dialysis initiation was not included in our analyses due to lack of data. Diuretic therapy plays a role in increasing urine volume; consequently lowering IDWG and the need for aggressive volume removal in

dialysis patients $[27,28]$. However, it is known that diuretics have no effect on renal urea and creatinine clearance in dialysis patients $[27,29,30]$. This suggests that the association of higher UFR with a decline in KRU may be less likely to be confounded by diuretics. While lower UFR appears to be associated with better outcomes in our study, insufficient UFR can also be related to inadequate fluid removal, leading to chronic volume overload and adverse outcomes. Therefore, it remains important to focus on patient factors such as salt and 
Fig. 3. Trajectory of KRU over time estimated by the expanded case mix-adjusted linear mixed-effects model. KRU, renal urea clearance.
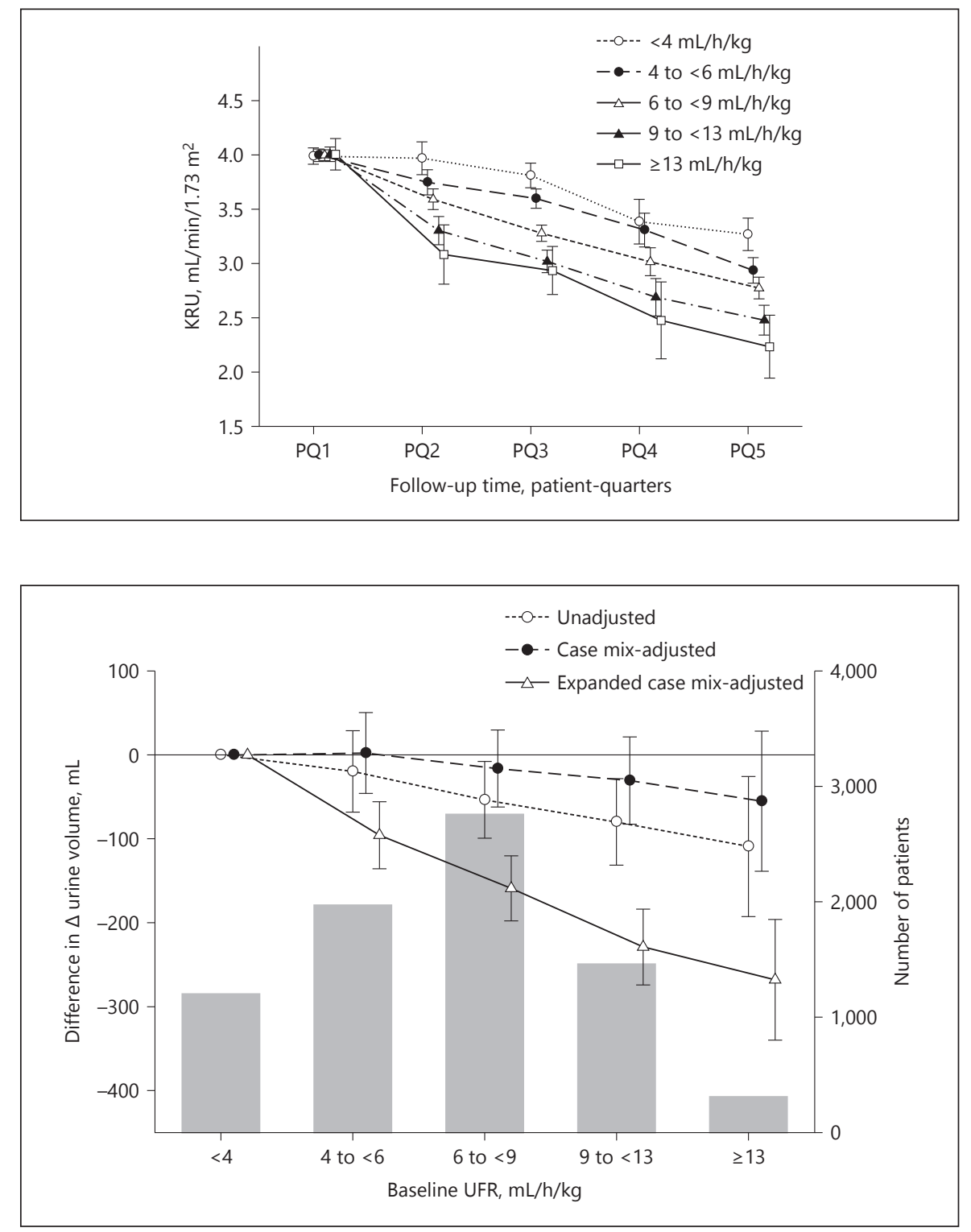

Fig. 4. UFR and difference in $\Delta$ urine volume during the first year after initiation of dialysis. UFR, ultrafiltration rate. fluid restriction to minimize IDWG and enable lower UFRs during dialysis treatments.

In conclusion, high UFR was associated with higher odds of a rapid decline in RKF, lower KRU, and lower urine output after 1 year among patients receiving conventional HD. Further clinical trials are needed to confirm and elucidate a causal effect of UFR on clinical outcomes among conventional HD patients.

\section{Acknowledgments}

We thank DaVita Clinical Research ${ }^{\circledR}$ for providing statistically deidentified data used in this study.

\section{Disclosure Statement}

K.K.-Z. has received honoraria and/or support from Abbott, Abbvie, Alexion, Amgen, American Society of Nephrology, AstraZeneca, AVEO, Chugai, Fresenius, Genetech, Haymarket Media, Hospira, Kabi, Keryx, National Institutes of Health, National Kidney Foundation, Relypsa, Resverlogix, Sanofi, Shire, Vifor, ZSPharma. C.P.K.: has received honoraria from Sanofi-Aventis, Relypsa and ZS Pharma.

\section{Funding Source}

K.K.-Z. is supported by NIH (NIDDK) grants K24-DK091419 and philanthropic grants from Mr. Harold Simmons, Mr. Louis Chang, Joseph Lee, and AVEO, Inc. 


\section{References}

1 Termorshuizen F, Dekker FW, van Manen JG, Korevaar JC, Boeschoten EW, Krediet RT; NECOSAD Study Group. Relative contribution of residual renal function and different measures of adequacy to survival in hemodialysis patients: an analysis of the Netherlands Cooperative Study on the Adequacy of Dialysis (NECOSAD)-2. J Am Soc Nephrol. 2004 Apr;15(4):1061-70.

2 Obi Y, Rhee CM, Mathew AT, Shah G, Streja E, Brunelli SM, et al. Residual Kidney Function Decline and Mortality in Incident Hemodialysis Patients. J Am Soc Nephrol. 2016 Dec; 27(12):3758-68.

3 Konings CJ, Kooman JP, Schonck M, Struijk DG, Gladziwa U, Hoorntje SJ, et al. Fluid status in CAPD patients is related to peritoneal transport and residual renal function: evidence from a longitudinal study. Nephrol Dial Transplant. 2003 Apr;18(4):797-803.

4 Marquez IO, Tambra S, Luo FY, Li Y, Plummer NS, Hostetter TH, et al. Contribution of residual function to removal of proteinbound solutes in hemodialysis. Clin J Am Soc Nephrol. 2011 Feb;6(2):290-6.

5 Pecoits-Filho R, Heimbürger O, Bárány $\mathrm{P}, \mathrm{Su}$ liman M, Fehrman-Ekholm I, Lindholm B, et al. Associations between circulating inflammatory markers and residual renal function in CRF patients. Am J Kidney Dis. 2003 Jun; 41(6):1212-8

6 Wang AY, Wang M, Woo J, Lam CW, Lui SF, Li PK, et al. Inflammation, residual kidney function, and cardiac hypertrophy are interrelated and combine adversely to enhance mortality and cardiovascular death risk of peritoneal dialysis patients. J Am Soc Nephrol. 2004 Aug;15(8):2186-94.

7 Suda T, Hiroshige K, Ohta T, Watanabe Y, Iwamoto M, Kanegae K, et al. The contribution of residual renal function to overall nutritional status in chronic haemodialysis patients. Nephrol Dial Transplant. 2000 Mar; 15(3):396-401.

8 Mathew AT, Fishbane S, Obi Y, Kalantar-Zadeh K. Preservation of residual kidney function in hemodialysis patients: reviving an old concept. Kidney Int. 2016 Aug;90(2):262-71.

9 Daugirdas JT. Dialysis hypotension: a hemodynamic analysis. Kidney Int. 1991 Feb;39(2): 233-46.
10 Saran R, Bragg-Gresham JL, Levin NW, Twardowski ZJ, Wizemann V, Saito A, et al. Longer treatment time and slower ultrafiltration in hemodialysis: associations with reduced mortality in the DOPPS. Kidney Int. 2006 Apr;69(7):1222-8.

11 Flythe JE. Ultrafiltration Rate Clinical Performance Measures: ready for Primetime? Semin Dial. 2016 Nov;29(6):425-34.

12 Stiller S, Thömmes A, Königs F, Schallenberg U, Mann H. Characteristic profiles of circulating blood volume during dialysis therapy. ASAIO Trans. 1989 Jul-Sep;35(3): 530-2.

13 Burton JO, Jefferies HJ, Selby NM, McIntyre CW. Hemodialysis-induced repetitive myocardial injury results in global and segmental reduction in systolic cardiac function. Clin J Am Soc Nephrol. 2009 Dec;4(12): 1925-31

14 Eldehni MT, Odudu A, McIntyre CW. Randomized clinical trial of dialysate cooling and effects on brain white matter. J Am Soc Nephrol. 2015 Apr;26(4):957-65.

15 McIntyre CW, Harrison LE, Eldehni MT, Jefferies HJ, Szeto CC, John SG, et al. Circulating endotoxemia: a novel factor in systemic inflammation and cardiovascular disease in chronic kidney disease. Clin J Am Soc Nephrol. 2011 Jan;6(1):133-41.

16 Flythe JE, Kimmel SE, Brunelli SM. Rapid fluid removal during dialysis is associated with cardiovascular morbidity and mortality. Kidney Int. 2011 Jan;79(2):250-7.

17 Assimon MM, Wenger JB, Wang L, Flythe JE. Ultrafiltration Rate and Mortality in Maintenance Hemodialysis Patients. Am J Kidney Dis. 2016 Dec;68(6):911-22.

18 Daugirdas JT. Physiologic Principles and Urea Kinetic Modeling. In: Daugirdas JT, Blake PG, Ing TS, editors. Handbook of Dialysis. 5th ed. Philadelphia: Lippincott Williams \& Wilkins; 2014.

19 Rubin DB. Multiple Imputation for Nonresponse in Surveys. New York (NY): Wiley; 1987.

20 Movilli E, Gaggia P, Zubani R, Camerini C, Vizzardi V, Parrinello G, et al. Association between high ultrafiltration rates and mortality in uraemic patients on regular haemodialysis. A 5-year prospective observational multicen- tre study. Nephrol Dial Transplant. 2007 Dec; 22(12):3547-52.

21 Cupples WA, Braam B. Assessment of renal autoregulation. Am J Physiol Renal Physiol. 2007 Apr;292(4):F1105-23.

22 Bidani AK, Griffin KA. Long-term renal consequences of hypertension for normal and diseased kidneys. Curr Opin Nephrol Hypertens. 2002 Jan;11(1):73-80.

23 Saran R, Li Y, Robinson B, Abbott KC, Agodoa LY, Ayanian J, et al. US Renal Data System 2015 Annual Data Report: Epidemiology of Kidney Disease in the United States. Am J Kidney Dis. 2016 Mar;67(3 suppl 1):Svii, S1305.

24 Jansen MA, Hart AA, Korevaar JC, Dekker FW, Boeschoten EW, Krediet RT; NECOSAD Study Group. Predictors of the rate of decline of residual renal function in incident dialysis patients. Kidney Int. 2002 Sep;62(3):104653.

25 Moist LM, Port FK, Orzol SM, Young EW, Ostbye T, Wolfe RA, et al. Predictors of loss of residual renal function among new dialysis patients. J Am Soc Nephrol. 2000 Mar;11(3): 556-64.

26 Kim TW, Chang TI, Kim TH, Chou JA, Soohoo M, Ravel VA, et al. Association of Ultrafiltration Rate with Mortality in Incident Hemodialysis Patients. Nephron. 2018; 139(1):13-22.

27 Medcalf JF, Harris KP, Walls J. Role of diuretics in the preservation of residual renal function in patients on continuous ambulatory peritoneal dialysis. Kidney Int. 2001 Mar; 59(3):1128-33.

28 Bragg-Gresham JL, Fissell RB, Mason NA, Bailie GR, Gillespie BW, Wizemann V, et al. Diuretic use, residual renal function, and mortality among hemodialysis patients in the Dialysis Outcomes and Practice Pattern Study (DOPPS). Am J Kidney Dis. 2007 Mar;49(3): 426-31.

29 Krediet RT, Douma CE, van Olden RW, Hodac-Pannekeet MM, Struijk DG. Augmenting solute clearance in peritoneal dialysis. Kidney Int. 1998 Dec;54(6):2218-25.

30 Chandna SM, Farrington K. Residual renal function: considerations on its importance and preservation in dialysis patients. Semin Dial. 2004 May-Jun;17(3):196-201. 